Article

\title{
A Methodological Framework for Assessing Practicability of the Urban Space: The Survey on Conditions of Practicable Environments (SCOPE) Procedure Applied in the Case Study of Cagliari (Italy)
}

\author{
Chiara Garau*D, Alfonso Annunziata and Mauro Coni \\ Department of Civil and Environmental Engineering and Architecture, University of Cagliari, \\ 09123 Cagliari, Italy; annunziata.alfonso@yahoo.it (A.A.); mconi@unica.it (M.C.) \\ * Correspondence: cgarau@unica.it; Tel.: +39-070-675-5565
}

Received: 8 October 2018; Accepted: 11 November 2018; Published: 14 November 2018

\begin{abstract}
Children's independent activities within public spaces emerge as a fundamental condition for their development considered in the context of their needs: socialization, movement, autonomy, and enrichment of their creative, imaginative, and cognitive potential. The promotion of their independence represents a relevant issue for implementing the smart city paradigm. This paradigm calls for a methodological framework where the urban fabric's performance is evaluated via comprehensive analytic protocols. The proposed study presents an audit tool for evaluating the quality of urban spaces in terms of their practicability by children: the Survey on Conditions of Practicable Environments (SCOPE). The practicability of this research is establishing the quality of urban spaces' usability, and it is expressed in terms of compositional, configurational, functional, and social factors of the built environment organized within a framework articulated in seven key dimensions (connectivity, convenience, comfort, commitment, conviviality, conspicuousness, and coexistence). The introduction of the concept of practicability and of indicators incorporating the demand for a children-sensitive perspective in the project of public spaces determine the novelty of the SCOPE procedure. This methodology was applied to an area in Central Cagliari, Italy, to evaluate the usability of public spaces. The results reveal that the proposed methodology is relevant for implementing the smart city paradigm because it addresses children's autonomy and their rights to the city by selecting and defining indicators to clarify and assess conditions of the built environment conducive to children's autonomy and independent social activities.
\end{abstract}

Keywords: urban spaces; smart city paradigm; Cagliari; children's autonomy

\section{Introduction}

Henri Lefebvre considers "the right to the city" [1] to be a phenomenon that implies the social ties, functions, services, and practicability of urban public spaces, as well as its vocation to satisfy the individual needs of all city users. The discourse on the contemporary city questions the significance of the public space as a privileged place for the exposure to diversity, for producing new experiences, and for the expression of individual identity $[2,3]$.

The quality of outdoor urban spaces, with young people in mind, is a growing global concern; as Mimi Kirk suggests, "by 2050 around 70 percent of people will be urbanized, and the majority of them will be under 18. Today, over a billion children are growing up in cities" [4]. For that reason, the practicability of outdoor spaces must not only be an indicator of the generic 
functionality of the city $[5,6]$, but also a condition for inclusion and equality to consolidate sustainable communities [7]. Practicability can be defined as the potential of the public urban space to promote children's independence by accommodating their independent social activities [6-11]. The concept of practicability incorporates not only the demand for a children-sensitive perspective in public spaces [6-16] but also the conceptualization of the inclusivity of public spaces as their potential to accommodate and enable children's independent mobility, and informal and structured, individual and collective ludic activities [6-8,10-12].

The issue of children's engagement in independent outdoor activities can be referred to the more general problem of a contemporary city's walkability. Walkability can be defined as the extent to which the urban environment is usable for pedestrians [17]. Concerns about walkability relate to a recognition of walking as a fundamental factor for promoting more sustainable, active, and inclusive communities $[18,19]$. The concept of practicability diverges from the notion of walkability because it emphasizes the importance of exploration and appropriation of public spaces through play as a condition for the development of children's cognitive, imaginative, and creative potential, and for the construction of their social and individual identities [8-11].

The concepts of walkability and practicability thus emphasize the concepts of autonomy $[6,9]$, capability [20-22], and affordance [23] as structural categories for the development of the urban public space [6-10,19-24]. Moreover, as a condition for their wellbeing, active citizenship, and integral development, the promotion of children's autonomy constitutes a relevant challenge for implementing the smart city paradigm [24]. In fact, this paradigm can be regarded as the prototype of a city that mobilises and uses its resources to improve its inhabitants' quality of life, while also promoting an anthropocentric approach and designing sustainable solutions to mitigate social and economic fragilities [22].

The smart city paradigm requires a methodological framework that evaluates the performance of the urban fabric via comprehensive analytic protocols. This study is thus aimed at elaborating an audit tool, the Survey on Conditions of Practicable Environments (SCOPE), for evaluating the quality of urban spaces in terms of their practicability for children. This tool is founded on a theoretical model based on concepts of autonomy, capability, and affordance. The practicability of urban spaces is operationalized in terms of a set of indicators related to microscale compositional, configurational, functional, and social factors of the built environment. The indicators are organized within a framework articulated in seven key dimensions (connectivity, convenience, comfort, commitment, conviviality, conspicuousness, and coexistence) [17], and are summarized in a synthetic index of practicability. The analytic tool is based on qualitative street audit and quantitative GIS-based indicators. This methodology was applied to an area in Central Cagliari, Italy, to evaluate the usability of public spaces.

The starting points of this research are the findings of a previous phenomenological study [24] developed in the form of a laboratory of urban explorations, aimed at identifying the spatial, material, morphological and functional characters and elements of the built environment that determine children's perception and experience of spaces.

Starting from these assumptions, a key question emerges related to the need to understand conditions of the built environment in order to encourage children's social, leisure activities and also children's autonomy and their capabilities. This paper analyses the existing literature on creating audit tools for evaluating the quality of the urban space, in relation to both its accessibility and walkability. Then, we present the SCOPE procedure, a methodological framework for assessing the practicability of spaces. In the subsequent sections, we describe a case study focused on an area in central Cagliari, Italy. Finally, the study results are revealed by identifying the performance level, in terms of practicability, of the analyzed spaces, as well as the critical aspects to be addressed. The paper concludes by considering the validity of results of the case study analysis and exploring the limitation of the proposed model as well its relevance for other similar contexts. 


\section{Literature Review}

Ludic activities, such as informal hobbies of small groups, such as hide-and-seek or exploring spaces, or football or cricket, promote the needs of childhood related to movement, autonomy, and socialization, while reinforcing the cognitive, imaginative, and creative potential, enhancing choice abilities, interpersonal and emotional skills and allowing children to acquire diverse communicative codes [8-11]. In particular, children's fruition of urban space through forms of play that encourage the exploration of spaces, manipulation and transformation of objects, and the occupation of space through movement, is essential for their development and for the development of their body scheme and the construction of their individual and social identities [8-11,23,25]. Studies developed at the Policy Studies Institute during different periods (1971, 1990, 2013) reveal that, for young people, experiencing independent activities within urban spaces is the most relevant opportunity for developing autonomy [6-9]. As a result, the child will also experience the unexpected, the ordinary, and the extraordinary, as well as limits and obstacles [6]. The value of independence to children's development also emerges from the Convention on the Rights of the Child [26]. Thus, constructing practicable public urban spaces that are organized to accommodate youngsters' independent leisure activities represents a relevant action to promote children's rights, their development as creative, autonomous, enterprising individuals, and to increase their quality of life.

The concept of practicability is here introduced as the potential of the public urban space to promote children's independence by accommodating their spontaneous social activities [6-11]. In fact, the notion of practicability integrates and modifies the notion of walkability $[17,20-22]$ by limiting the composition of the groups of users considered, and by enlarging its scope, in terms of uses and activities focusing on: (a) the needs and practices of children; (b) the potential of spaces to accommodate and enable children's independent mobility and informal and structured, individual, and collective ludic and leisure activities $[6,8-10,23]$. Further, practicability is proposed as a fundamental objective for planning the public urban space. As a result, emphasizing the notion of practicability as the objective for creating outdoor urban spaces requires a renewed theoretical model of the relationship between individuals and the built environment.

From this perspective, the concepts of autonomy, affordance, and capability are recognized as structural and fundamental categories. Autonomy [6,8] is defined as the capacity to govern oneself without external guidance by creating specific rules of behavior and then fulfilling them. Affordance [23] can be defined as elements that promote and structure patterns of action within a space. Affordances can be potential, perceived, shaped, or utilized. A potential affordance can be shaped or utilized only if a specific use or a contact occur. Affordances are relational, and are signified according to situational or physical circumstances and motivational needs and abilities. Capability is described as a valuable state of being or a condition that a person can access [20-22,27]. In particular, an urban capability, as a dimension of overall human capabilities, can be defined as the potential for an individual to access opportunities or affordances deemed as valuable. Capability requires two preconditions: ability, as an individual's internal potential to do or to be; and opportunity, as the presence of material, contextual conditions that motivate the individual to exercise their internal potential. The spatial and functional features of the built environment influence capability by determining an opportunity's dimension [20,21]. In reference to the concepts of capability, affordance, and autonomy, the SCOPE procedure measures whether, and to what extent, the material, spatial, and contextual conditions of urban spaces are conducive to reinforcing children's autonomy and to increasing their capabilities, by incorporating opportunities and affordances for spontaneous, structured, individual, or collective leisure and ludic activities. This potential of urban spaces is referred to as practicability.

Recently, many researchers have focused on the definition of methodologies aimed at describing the complex interactions between the built environment and individuals in determining the walking behaviours of the latter. Research on walkability is a pertinent contribution to our research, since walking is not simply a mode of movement, but a complex act conveying different levels of significance [28]. 
Tools for measuring walkability can be grouped in several categories, reflecting different approaches: web based tools (Walkscore, Walkshed, Walkonomics,) [17,20,21,29], focused on quantitative evaluations of macroscale factors, such as intersection density, population density, and distance from amenities; multicriteria evaluation models, that combine spatial information and evaluation of microscale urban design features [17,30]; audit tools, based on quantitative and qualitative evaluation of urban design microscale features of routes and of route segments (Pedestrian Environment Data Scan (PEDS); Systematic Pedestrian and Cycling Environmental Scan instrument (SPACES); Microscale Audit of Pedestrian Streetscapes (MAPS-Global) Environmental Assessment of Public Recreation Spaces (EAPRS)) [31-34]; and questionnaires, focused on reporting pedestrians' perceptions and preferences related to significant spatial, environmental, and social properties of the urban space (Neighbourhood Environment Walkability Survey (NEWS)) [35].

In the following section, methodologies for assessing the walkability of urban spaces are discussed, in order to individuate the development of the perspectives incorporated and emerging aspects, criteria, and indicators relevant for the proposed research on the usability, by children, of public spaces.

\section{Criteria for Evaluating the Practicability of the Urban Space}

The concept of walking as a multidimensional act, which implies an attitude of openness and a connection with the human and spatial context [36], is recognizable in recent research on walkability assessment methodologies. In particular, the research conducted by Blecic et al. [20] underlies a paradigm shift from the notion of mobility to the concept of accessibility. The concept of accessibility can be regarded as a multi-dimensional concept [20,21,37]. Its different conceptualizations incorporate the opportunity dimension implied by the notion of capability or embrace the concept of affordance; accessibility is defined either as potential for interaction or as the actual freedom to participate to different activities, thus partially overlapping with the definition of opportunity. In particular, when considered as a potential for action depending on functional, material, and configurational elements of spatial structures in relation to individual factors and users' abilities, it implies an affordance. Geurs and Van Wee observe that the concept of accessibility incorporates four dimensions [37]: a transport component, a land-use component, a temporal component, and an individual component. This quality of accessibility compels us to consider urban design factors, microscale spatial features of the built environment, land-use patterns, and social factors as variables that influence individual practices and attitudes. Based on these theoretical premises, the analytical methods proposed by Garau and Pavan [22], Jabbari et al. [38], Blecic et al. [20,21], Moura et al. [17], Talavera-Garcia and Soria-Lara [39], and Ewing and Handy [40,41] are thus regarded as valid contributions for selecting criteria and structuring the methodology for assessing practicability.

Further research, by Battista and Manaugh [42] in particular, reveals the need to account for socio-demographic factors as fundamental features of the urban environment, and also for individual factors to mediate pedestrians' practices and perceptions. As main issues, other research also regards the selection of pertinent criteria, the individuation of relevant, applicable, and understandable indicators [22,39], and the determination of their relative importance [17]. Moreover, these aspects are influenced by the scale of the analysis, the purpose of users' trips, and the social groups considered. Finally, protocols of verification or validation are required to determine if available tools are accurate measures of urban walkability.

Moreover, categorizing built environment factors and the relative indicators emerges as a fundamental step in order to structure the evaluation methodology. Solid contributions are represented by the 3Ds layout proposed by Cervero and Kochelman [43] — density, diversity, and design—and reconfigured as a five-dimensional structure, adding distance to transit and destination to accessibility by Ewing et al. [44]. Alternative structures include different categories, depending on the purpose and scale of the proposed analysis: attractiveness, safety, comfort, and accessibility are elements of the Q-PLOS (Quality of Pedestrian Level of Service) assessment procedure [39]; environment, pedestrian facility, road attributes, and walking environment are central to the PEDS evaluation 
tool [31]; and use and fruition, health and wellbeing, appearance, management, environment, and safety and security articulate the Indicator of Smart Urban Quality (ISUQ), proposed by Garau and Pavan [22]. The 5Cs layout [45,46], is a multidimensional framework proposed by the London Planning Advisory Committee, which states that a practicable pedestrian environment should be connected, convivial, convenient, comfortable, and conspicuous. Moura et al. added to these categories the further dimensions of commitment and coexistence [17].

These categories are specified and adapted, according to the particular purpose of the assessment methodology discussed here, to capture built environment variables conducive to children's intense and independent use of the public space $[17,22,45,46]$. Connectivity is thus described as the extent to which an urban public space is integrated in a continuous network of walkable surfaces within the arterial network of the collective transportation routes. Convenience refers to the extent to which an urban space offers access to different amenities, services, and opportunities to participate in social activities. Comfort measures the effects of microclimatic and environmental conditions, treatment of surfaces, and geometric and constructive features of pedestrian facilities to increase people's sense of wellbeing and fulfil the needs of different users related to their abilities and purposes.

Conviviality refers to the extent to which the public space promotes contact among individuals and favours contaminations and synergies among the necessary, recreative, and social activities, which activate self-reinforcing processes that support the vitality of the urban space. Conspicuousness reflects the extent to which public spaces are imageable, interesting, and inviting, in terms of spatial legibility, complexity, and coherence. Coexistence refers to the impact of traffic on the potential of the public space to accommodate children's independent, recreative, and social activities. Finally, commitment refers to factors indicative of the engagement, responsibility, and liability of local agencies toward the promotion of children's independent mobility and activities across public spaces. The seven categories operationalize the concept of practicability and define distinct dimensions of material, spatial, and functional conditions of the built environment that incorporate affordances and opportunities for children's social leisure activities. In addition, the seven categories thus define a structure aimed at organizing the indicators; the categories are therefore instrumental in articulating the understanding of opportunities incorporated in the built environment that increase children's capabilities, that is their possibilities of participating to activities deemed as valuable. Autonomy is an experience central to the development of children emerges as a consequence of the possible interactions with spatial and material structures and with other individuals.

Building upon these premises, the authors developed an assessment framework of the practicability of urban public spaces for children, the Survey of Conditions for Practicable Environments (SCOPE). This methodology limits the scope of the user dimension, considered by previous studies, focusing on the interactions among children and the built environment, and enlarges the activity dimension, by considering conditions of the built environment conducive not only to independent mobility, but, in particular, to children's leisure and social activities. In the subsequent section, the authors describe a five-step procedure that structures the practical application of the discussed assessment methodology.

\section{Methodology: The SCOPE Procedure}

The SCOPE assessment framework combines secondary, digitized data analysis and on-street surveys to assess microscale factors determining the potential of the public space to accommodate children's independent activities. The procedure consists of five stages: selection and characterization of the case study; structuring of the evaluation; selection of the indicators; data collection and evaluation of the indicators; and scoring and aggregation of the indicators.

The selection and characterization of the case study refers to the definition of the purpose and scale of the analysis, the selection of a set of relevant public urban spaces, their contextualization within the urban structure, and the recognition of available digitized data. The analysis can be structured either as a survey of local public spaces within a homogeneous portion of the urban space, or as a comparison 
(in terms of practicability levels of relevant public spaces) of different districts, characterised by specific land use patterns, configuration of urban structures, demography, and typology of buildings.

The evaluation structure implies, for each category individuated in the seven-dimensional layout, the selection of a set of parameters, or key concerns, indicative of relevant properties of the built environment. These properties are selected as the most conducive to reinforcing children's independence and tendency for outdoor public space activities. This selection process is based on a broad literature review and on stakeholder sessions from a workshop of urban explorations, which involved 42 children ranging from 5 to 13 years of age. The literature review consisted of an analysis of 38 journal papers, published from 2009 to 2018, and of 14 assessment tools, incorporating theoretical frameworks and methodologies derived from different disciplinary fields, from urban design, to urban planning and preventive medicine. These references are individuated through a comprehensive research of on-line databases (Google Scholar, Scopus, Web of Science), setting as research parameters the terms children, walkability, assessment, quality, urban space, and smart city. The set of parameters that emerged from the literature review is thus integrated and re-defined through the analysis of findings from the stakeholder sessions. The workshop was articulated in three sessions of direct observation of relevant places, representative of different categories of urban public spaces-the district, the node, the edge, and the route-and in a focus group. This preliminary research stage was based on the saturation principle and on the phenomenological approach as underlined in Annunziata and Garau (2018) [24]. Data collection methods included the observation of children's activity patterns across spaces, and the analysis of notes, sketches, and interviews, to understand spatial elements and conditions in determining children's perception of spaces and their tendency for independent activities within public urban spaces [24].

The third stage is focused on the selection of the indicators for each of the seven categories (Table 1). For each parameter, potential indicators and sub-indicators are collected from a comprehensive literature review. This process is described in Annunziata and Garau 2018 [24].

Table 1. List of selected indicators related to specific built environment properties and grouped in seven categories according to the SCOPE layout.

\begin{tabular}{|c|c|c|}
\hline Category & Parameters & Indicators \\
\hline \multirow{3}{*}{ Connectivity } & Accessible pedestrian network & Presence of barriers \\
\hline & Coarseness & Intersection density \\
\hline & Access to collective transport & Proximity of collective transport nodes \\
\hline \multirow{4}{*}{ Convenience } & Effective width of pedestrian routes & Effective width \\
\hline & Land-use diversity & Walkscore index \\
\hline & Available destinations & Density of retail activities and services \\
\hline & Availability of basic services & $\begin{array}{l}\text { Number of distinct commerce and services used } \\
\text { on a daily basis }\end{array}$ \\
\hline \multirow{12}{*}{ Comfort } & Vigilance & Percentage of first floor windows \\
\hline & Illumination & $\begin{array}{l}\text { Degree of illumination of the pedestrian facilities } \\
\text { along the longitudinal dimension }\end{array}$ \\
\hline & Antisocial practices & Frequency of anti-social practices \\
\hline & Pavement quality & Condition of pedestrian surfaces/pavements \\
\hline & Slope & Longitudinal slope \\
\hline & Lavatories & Available lavatories \\
\hline & Fountains & Available fountains \\
\hline & Vegetation & Trees coverage \\
\hline & Urban water features & $\begin{array}{l}\text { Available water bodies incorporated in public } \\
\text { space design }\end{array}$ \\
\hline & Acoustic environment & Quality of the acoustic environment \\
\hline & Olfactory environment & Quality of the olfactory environment \\
\hline & Microclimatic conditions & Variety of micro-climatic conditions \\
\hline
\end{tabular}


Table 1. Cont.

\begin{tabular}{|c|c|c|}
\hline Category & Parameters & Indicators \\
\hline \multirow{10}{*}{ Conviviality } & Meeting places & Presence of meeting places \\
\hline & $\begin{array}{l}\text { Anchor places (e.g., shopping malls, public } \\
\text { facilities, and transport interfaces) }\end{array}$ & Existence or visibility of anchor places \\
\hline & $\begin{array}{l}\text { Service hours (e.g., restaurants, bars, } \\
\text { cinema, etc.) }\end{array}$ & $\begin{array}{l}\text { Existence of activities with extended service } \\
\text { hours }\end{array}$ \\
\hline & $\begin{array}{l}\text { Spatial and functional continuity between } \\
\text { the street and the surrounding building } \\
\text { and space }\end{array}$ & Level of integration \\
\hline & Intergenerational activities & Levels of interactions \\
\hline & Regions (clusters) of space for play & Availability of clusters of space for play \\
\hline & Pieces of furniture and partitions to play & Availability of furniture and partitions to play \\
\hline & Play set & Availability of play set or structure features \\
\hline & Informal seats & Availability of informal seats \\
\hline & Seats & Availability of resting/sitting features (benches) \\
\hline \multirow{5}{*}{ Conspicuousness } & Imageability & Imageability \\
\hline & Enclosure & Degree of enclosure \\
\hline & Human scale & Human scale \\
\hline & Articulation of edges & Articulation of edges \\
\hline & Complexity & Complexity \\
\hline \multirow{3}{*}{ Coexistence } & Traffic safety (at pedestrian crossings) & Safety \\
\hline & Priority of pedestrians & Priority of pedestrians \\
\hline & Barrier effect & Traffic speed limits and number of lanes \\
\hline \multirow{4}{*}{ Commitment } & Planned public space design interventions & Implementation of design standards \\
\hline & Planted areas & Management of planted area \\
\hline & Garbage cans & Availability of garbage cans \\
\hline & $\begin{array}{l}\text { Maintenance of pedestrian } \\
\text { surfaces/facilities }\end{array}$ & $\begin{array}{l}\text { Level of maintenance of pedestrian } \\
\text { surfaces/facilities }\end{array}$ \\
\hline
\end{tabular}

Among these, depending on the scale and purpose of the targeted analysis, and on availability of reliable secondary data, a specific indicator and, if required, a set of related sub-indicators, is selected to assess and measure each parameter.

The process of selecting relevant indicators is structured around: criteria of objectivity (indicators must be clear, unambiguous, and precise); relevance (significance and pertinence to the focus of the analysis, i.e., the concept of practicability); measurability and reproducibility (indicators must be quantitative and systematically observable); validity (implying possibility of verification and data quality control); representativeness, comparability over time, and applicability (possibility of use of findings from previous research and existence of accessible databases); and understanding (indicators must be easy to understand by the target public, i.e., by decision-makers and the general public) [22].

The subsequent stage in the SCOPE procedure is aimed at data collection and evaluation of indicators. Data are retrieved mainly from available data sets and are collected and merged in the Geographic information system (GIS) platform. Urban spaces selected for the assessment, as well as related features and relevant items, are individuated on a map of the urban network, previously built on detailed 1:10,000 digitized maps available from the Sardinia Regional Informative Territorial Service. The urban network map is then integrated and validated through the systematization of data collected from the Open Street Map platform, internet-based street level imagery services (Google Street View), and territorial imagery services (Google Maps, Google Earth, Bing Maps), and from direct observations during on-street surveys.

A calculation sheet is created for each selected public space, and is organized according to the evaluation framework layout. This structure formalizes relationships among categories, parameters, 
and indicators. For each indicator, it also incorporates indications on the unit of measure or the evaluation scale, as well as the range of values, scales, related scores, and levels of performance. If required, the definitions, criteria for assessing qualitative indicators, and queries for measuring quantitative indicators, by means of GIS-platform processing tools, are also included. Finally, the scoring stage is aimed at aggregating measurements and assessments determined for single indicators, to develop a synthetic indicator related to each category and a global index of practicability of the urban spaces.

Since the proposed methodology incorporates both qualitative and quantitative indicators, different measurements, and assessments of single indicators must be normalized and formalized in homogeneous quantitative terms.

As a result, with regard to the qualitative indicators, we define a procedure for assigning a score to each scale level established for each indicator. Finally, for each quantitative indicator, a range of values is determined and a score, ranging from 0.1 to 0.8 is assigned to each value band (Table 2).

Table 2. Examples of indicators and scoring procedures.

\begin{tabular}{|c|c|c|c|c|}
\hline Indicator & Type & Measurement & Scale & Score \\
\hline Intersection density & Quantitative & $\begin{array}{l}\mathrm{D}=\left(\sum \mathrm{D}_{\mathrm{i}}\right) /(\mathrm{n}-1) \\
\mathrm{D}=\text { Average intersection distance } \\
\mathrm{D}_{\mathrm{i}}=\text { ith value of distance among } \\
\text { consecutive intersections } \\
\mathrm{n}=\text { number of intersections }\end{array}$ & $\begin{aligned} D & \leq 100 m \\
150 m & \geq D>100 m \\
200 m & \geq D>150 m \\
250 m & \geq D>200 m \\
D & >250 m\end{aligned}$ & $\begin{array}{l}0.8 \\
0.6 \\
0.5 \\
0.3 \\
0.1\end{array}$ \\
\hline $\begin{array}{l}\text { Density of retail } \\
\text { activities and services }\end{array}$ & Quantitative & $\begin{array}{l}\mathrm{r} / 100 \mathrm{~m} \\
\mathrm{r}=\text { Number of retail activities }\end{array}$ & $\begin{array}{l}20 \geq \mathrm{r} / 100 \mathrm{~m}>16 \\
16 \geq \mathrm{r} / 100 \mathrm{~m}>12 \\
12 \geq \mathrm{r} / 100 \mathrm{~m}>8 \\
8 \geq \mathrm{r} / 100 \mathrm{~m}>4 \\
4 \geq \mathrm{r} / 100 \mathrm{~m} \geq 0\end{array}$ & $\begin{array}{l}0.8 \\
0.7 \\
0.5 \\
0.3 \\
0.1\end{array}$ \\
\hline Integration [47] & Qualitative & $\begin{array}{l}\text { Spatial and functional continuity } \\
\text { among pedestrian facilities and } \\
\text { buildings enclosing public spaces }\end{array}$ & $\begin{array}{l}\text { Integrated } \\
\text { Filtered } \\
\text { Separated }\end{array}$ & $\begin{array}{l}0.8 \\
0.5 \\
0.1\end{array}$ \\
\hline Levels of interaction & Qualitative & $\begin{array}{l}\text { Presence of users of distinct age } \\
\text { groups }\end{array}$ & $\begin{array}{l}\text { Mostly to extremely } \\
\text { To some extent } \\
\text { Not }\end{array}$ & $\begin{array}{l}0.8 \\
0.5 \\
0.1\end{array}$ \\
\hline $\begin{array}{l}\text { Articulation of edges } \\
\text { [48] }\end{array}$ & Qualitative & $\begin{array}{l}\text { Presence and patterns of spatial } \\
\text { interfaces, elements, or transition } \\
\text { spaces constituting the edge of } \\
\text { pedestrian facilities }\end{array}$ & $\begin{array}{l}\text { Articulated } \\
\text { Varied } \\
\text { Reinforced } \\
\text { Regular } \\
\text { Not defined } \\
\text { Absent }\end{array}$ & $\begin{array}{l}0.8 \\
0.7 \\
0.6 \\
0.5 \\
0.3 \\
0.1\end{array}$ \\
\hline
\end{tabular}

A synthetic index is then calculated for each category as the average of the scores assigned to the related indicators. Values calculated for the synthetic indices range from 0.1 to 0.8 (Table 3) [20].

Table 3. Examples of attribution of scores to the category synthetic indicators.

\begin{tabular}{clccc}
\hline $\begin{array}{c}\text { Synthetic } \\
\text { Indicator }\end{array}$ & \multicolumn{1}{c}{ Measurement } & Scale & Score & $\begin{array}{c}\text { Level of } \\
\text { Performance }\end{array}$ \\
\hline \multirow{4}{*}{$\mathrm{I}_{\mathrm{Ci}}$} & $\mathrm{I}_{\mathrm{Ci}=\mathrm{M}_{\mathrm{i}}=\left(\sum \mathrm{S}_{\mathrm{j}}\right) / \mathrm{n}_{\mathrm{i}}}$ & $0.80 \geq \mathrm{M}_{\mathrm{i}} \geq 0.70$ & 0.8 & Excellent \\
& $\mathrm{Sj}=\mathrm{Score}$ for the jth indicator & $0.69 \geq \mathrm{M}_{\mathrm{i}} \geq 0.55$ & 0.6 & Good \\
& $\mathrm{n}=$ Number of indicators of the & $0.54 \geq \mathrm{M}_{\mathrm{i}} \geq 0.40$ & 0.5 & Fair \\
& ith category & $0.39 \geq \mathrm{M}_{\mathrm{i}} \geq 0.20$ & 0.3 & Insufficient \\
& & $0.19 \geq \mathrm{M}_{\mathrm{i}} \geq 0.10$ & 0.1 & Poor \\
\hline
\end{tabular}

Finally, an aggregated indicator for the practicability of an urban space, the ISCOPE indicator, is determined as the sum of the synthetic indices measured for each category. Scores measured for the $\mathrm{I}_{\mathrm{SCOPE}}$ index range from 0.7 to 5.6 and are grouped in five ranges of values, representative of poor conditions of practicability (Table 4). 
Table 4. Range of values for the ISCOPE index.

\begin{tabular}{cccc}
\hline Index of Practicability & Measurement & Scale & Conditions of Practicability \\
\hline & & $4.9-5.6$ & Excellent \\
& $\sum \mathrm{I}_{\mathrm{Ci}}$ & $3.9-4.8$ & Good \\
& & $2.9-3.8$ & Fair \\
\hline & & $1.5-2.8$ & Insufficient \\
& & $0.7-1.4$ & Poor \\
\hline
\end{tabular}

At this stage, a fundamental issue emerged regarding the definition of threshold values, according to which the ranges of values, specified for the quantitative indicators, are established. The quality thresholds are based on results and findings of previous studies conducted on the vitality of the public space. For instance, ranges of values, determined to assign a score to the sub-indicator "extent of free surfaces," are defined according to Jan Gehl's concept of the visual field in the historic city and of the social distances that influence significance and the content of interactions among individuals [19,49].

Moreover, the ranges of values determined for the intersection density indicator are interpolated from the $200 \mathrm{~m}$ block length threshold, established by Jane Jacobs as the maximum acceptable distance between intersections to provide adequate alternative routes for daily or frequent pedestrian movements (Table 2) [49]. Ranges of values for the commercial density indicator, formalized as the number of retail units per $100 \mathrm{~m}$ of linear development of façades delimiting the public space, are determined, according to Talavera and Garcia [39], as equal intervals based on the maximum value observed in the area selected for the analysis. The value determined, equal to 20 retail units per $100 \mathrm{~m}$, is coincident with the density value assumed by Gehl [19] as the optimal condition for increasing diversity and vitality of the public space and for enriching the pedestrian experience (Table 2).

While it is evident to which specific aspect or content of the built environment many indicators refer, other indicators must be more precisely defined. In particular, the integration indicator measures the degree of spatial and functional continuity between the pedestrian space and buildings and area enclosing the public space.

The articulation of edges indicator describes if and how the alignment of buildings, and aspects of spatial elements, create sequences of spatial conditions along the perimeter of the public spaces that reinforce the border effect and increase opportunities for pedestrian interactions. The availability of regions of space for play indicator describes if and to what extent the morphology, scale, articulation, and distribution of public space activities determine accessible and unstructured areas apt to accommodate children's different social activities. This indicator is determined by assessing a set of sub-indicators that measure the extent and morphological regularity of available spaces and verify the implementation of restrictions on public space use.

Imageability, according to Lynch [50], can be defined as the particular quality of an urban space that produces a vividly identified, strongly structured, and useful mental image of the built environment. Thus, the imageability indicator measures to what extent the presence or visibility of reference points determine a space as distinctive, recognizable, and memorable. These reference points may refer to distinct landscape elements, major landscape features, historic buildings, singular elements, or outdoor activities [40].

Enclosure can be described as the degree to which vertical elements of the built environment define and organize an urban space, delimiting the visual field and structuring the individual space $[19,40]$. The human scale refers to the particular quality of the urban space whose elements, textures, and structures are designed and arranged according to the dimensions of the human body, the speed of its movements, and the range and organization of its sensory organs $[19,40]$.

Finally, complexity refers to the plurality and organised co-existence of elements, conditions, differences, and relations within the public space. 
The related indicator measures to what extent the following factors can reinforce a space's visual richness: the variety of spatial conditions, combination of details and textures of different scales, variability of perceptible qualities of elements, presence of art work, and re-generation of banal elements or surfaces and colours. In the subsequent paragraphs, the authors illustrate the case study of Cagliari and the application of the methodologies described.

\section{Cagliari, Italy and Applications to Case Studies}

Cagliari forms the core of the Metropolitan City of Cagliari, a polycentric settlement structure comprising 17 municipalities and characterized by a complex pattern of communication and social dependence. Cagliari emerged as an optimal case study, because of its rich tradition of policies and projects developed to promote children's rights related to accessibility and participation. In 2014, in connection with the program "Child Friendly Cities" promoted by Unicef Italy, the city drafted the document "Costruire Città amiche dei bambini" [25], inspired by the principles of the Declaration of Rotterdam [51].

This document committed the local authorities to promoting child-oriented urban planning and design, by encouraging children's participation and by creating safe, well-lit public spaces. After this initiative, several programs developed initiatives to promote children's mobility, in particular concerning home-to-school itineraries (Pedibus and à peis programs). These projects are in line with more general policies aimed at fostering independent mobility [52], including the introduction of a bicycle-sharing service, extension of the bicycle path network, and reorganization of public open spaces. This last action is articulated in the pedestrianisation of different areas within Cagliari (e.g., Villanova and Marina districts) and of roads (e.g., Corso Vittorio Emanuele, starting from 2016), and in the revitalization of significant outdoor urban places (e.g., via Manno, piazza Garibaldi, and piazza San Michele, starting from 2017). In addition, several social and cultural organisations, such as Associazione Efys, Associazione CoSas, Associazione Ciclofficina Sella del diavolo, and Associazione Punto Zero, operate to foster children's creativity, socialization, active citizenship, and participative knowledge of Cagliari. These objectives are pursued through the following initiatives: photography and urban exploration workshops (through the project "Esplora Città," 2013); territorial mapping laboratories (through the project called "Ci sono più posti che strade," 2017); and temporary appropriation through informal collective forms of play of relevant urban places [24]. As a result, the study builds on the methodologies and findings of these various workshops and projects.

The study focused on a large urban area of Cagliari, that includes part of the historic districts of Stampace, Marina, and Villanova (Figure 1). The choice of these districts depends on three factors: (1) high population density (4260 in $/ \mathrm{km}^{2}, 12,258 \mathrm{in} / \mathrm{km}^{2}, 14,494 \mathrm{in} / \mathrm{km}^{2}$, respectively); (2) variety of functions and services, such as residential, political, and administrative functions, and commercial activities, which encourage a constant flow of people throughout the day; and (3) continuity of spaces partly or entirely closed to vehicular traffic. The criterion is to concentrate analysis on spaces in which certain fundamental conditions are verified for reinforcing walkability and children's autonomy. These conditions are: limited environmental dangers, priority of pedestrians, plurality, intensity and liveliness of spaces, and variety of stimuli [49]. Among the spaces individuated as relevant places during the workshop of urban explorations [24], six spaces-Piazza del Carmine, Piazza Yenne, Piazza Savoia, Calata Darsena, Piazza Matteotti, and the Regional Council Building—are identified and are thoroughly analyzed employing the SCOPE procedure. These spaces are selected according to three criteria: centrality within the public debate; significance as context of practices and activities of diverse groups of users; relevance for children, of distinctive spatial elements or features and of leisure practices related to these spaces, resulting in significant collective experiences and in a sense of connectedness to places. 


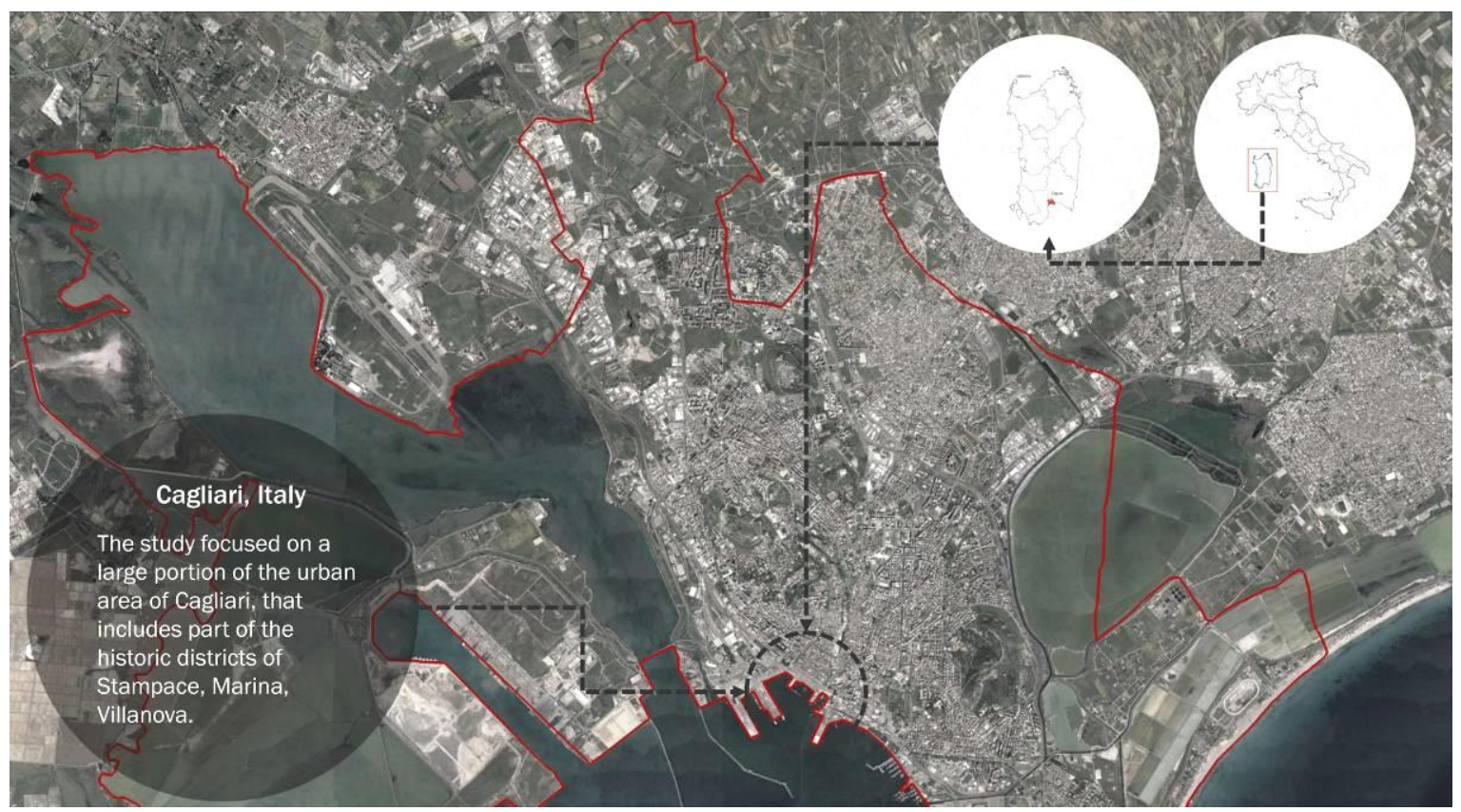

Figure 1. Cagliari: Representation of urban spaces explored during the study. The red line delimits the boundary of the municipality of Cagliari. The area of study is within the black circle.

\section{Results}

Children's informal and independent activities were viewed as a function of properties related to connectivity, convenience, comfort, conviviality, conspicuousness, and coexistence of different forms of movement and commitment. In particular, the analysis shows that the selected spaces were characterized by a fair and adequate global level of practicability, as indicated by values of the ISCOPE index varying from 2.8 to 4.9 , on a scale ranging from 0.7 to 5.6 (Table 5).

Table 5. Results for the Synthetic Category Indicators and for the Global Index ISCOPE.

\begin{tabular}{|c|c|c|c|c|c|c|}
\hline \multirow{2}{*}{ Indicators } & \multicolumn{6}{|c|}{ Selected Urban Spaces } \\
\hline & $\begin{array}{c}\text { Piazza Del } \\
\text { Carmine }\end{array}$ & $\begin{array}{l}\text { Piazza } \\
\text { Yenne }\end{array}$ & $\begin{array}{l}\text { Regional Council } \\
\text { Building }\end{array}$ & $\begin{array}{c}\text { Calata } \\
\text { Darsena }\end{array}$ & $\begin{array}{l}\text { Piazza } \\
\text { Savoia }\end{array}$ & $\begin{array}{c}\text { Piazza } \\
\text { Matteotti }\end{array}$ \\
\hline Connectivity $\mathrm{I}_{\mathrm{C} 1}$ & 0.6 & 0.6 & 0.8 & 0.8 & 0.8 & 0.6 \\
\hline Convenience $\mathrm{I}_{\mathrm{C} 2}$ & 0.5 & 0.6 & 0.5 & 0.6 & 0.8 & 0.5 \\
\hline Comfort $\mathrm{I}_{\mathrm{C} 3}$ & 0.5 & 0.5 & 0.5 & 0.5 & 0.5 & 0.3 \\
\hline Conviviality $\mathrm{I}_{\mathrm{C} 4}$ & 0.5 & 0.6 & 0.6 & 0.6 & 0.6 & 0.3 \\
\hline Conspicuousness $\mathrm{I}_{\mathrm{C} 5}$ & 0.5 & 0.6 & 0.6 & 0.3 & 0.6 & 0.5 \\
\hline Coexistence $\mathrm{I}_{\mathrm{C} 6}$ & 0.3 & 0.3 & 0.6 & 0.3 & 0.8 & 0.3 \\
\hline Commitment $\mathrm{I}_{\mathrm{C} 7}$ & 0.6 & 0.5 & 0.5 & 0.8 & 0.8 & 0.3 \\
\hline Global Index ISCOPE & 3.5 & 3.7 & 4.1 & 3.9 & 4.9 & 2.8 \\
\hline
\end{tabular}

The utilization of relevant aspects of the built environment through measurable indicators also facilitated the identification of specific issues, and thus, determined objectives and requirements for revitalization and improvement (Figure 2). 


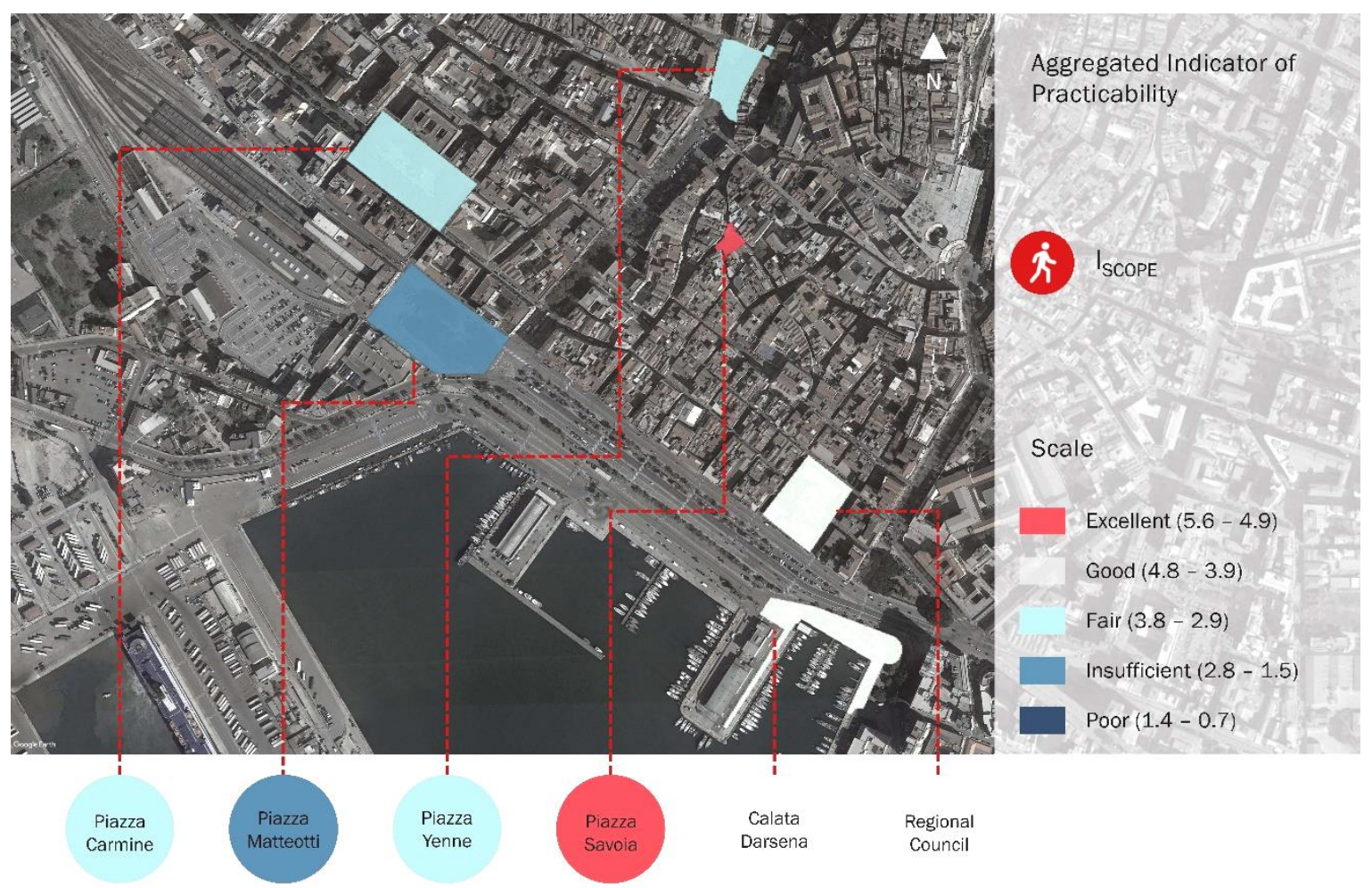

Figure 2. Distribution of values for the ISCOPE index: representation of practicability levels of the selected urban spaces.

The similarity of results could be attributed to the homogeneous characteristics of the urban structure in which these spaces are located. In particular, the prevalent functional, configurational, and morphological features of the Cagliari central area resulted in high values for the connectivity synthetic indicator $\mathrm{I}_{\mathrm{C} 1}$ (Figure 3).

These values depended on the porosity of the urban structure, captured by the intersection density indicator, and on the concentration of interfaces between the collective transport network and pedestrian spaces.

A negative element was represented by the presence of several barriers (steps, pieces of furniture, and road signs) that reduced the width of pedestrian routes along the edges of: Piazza del Carmine, in Piazza Matteotti, in front of the bus station and railway station, and along the west side of Piazza Yenne. Moreover, the land-use pattern distinctive of the Cagliari central area, resulting in the concentration and combination of primary and secondary uses, determined high walkscore index values, ranging from 98 to 100 .

The walkscore index was here considered, not as a proxy of walkability, but as a land-use diversity indicator. It was incorporated in the convenience category, and measured the concentration of functions, services, commercial activities, and amenities located within a short distance from a specific place. The walkscore score was also selected in order to provide a quantitative, objective measurement of the accessibility of different amenities while reducing time consumption. Nevertheless, values for the convenience synthetic indicator $\mathrm{I}_{\mathrm{C} 2}$ were more contained. In particular, these values were reduced by the modest density of services, commercial activities, and leisure activities along the neighbourhood edges_in particular, Piazza Matteotti, Piazza del Carmine, and Calata Darsena—and/or by the modest width of pedestrian routes, in particular along the edges of Piazza del Carmine, the west side of Piazza Yenne, and the edges of the pedestrian space under the Regional Council Building (Figure 3). 

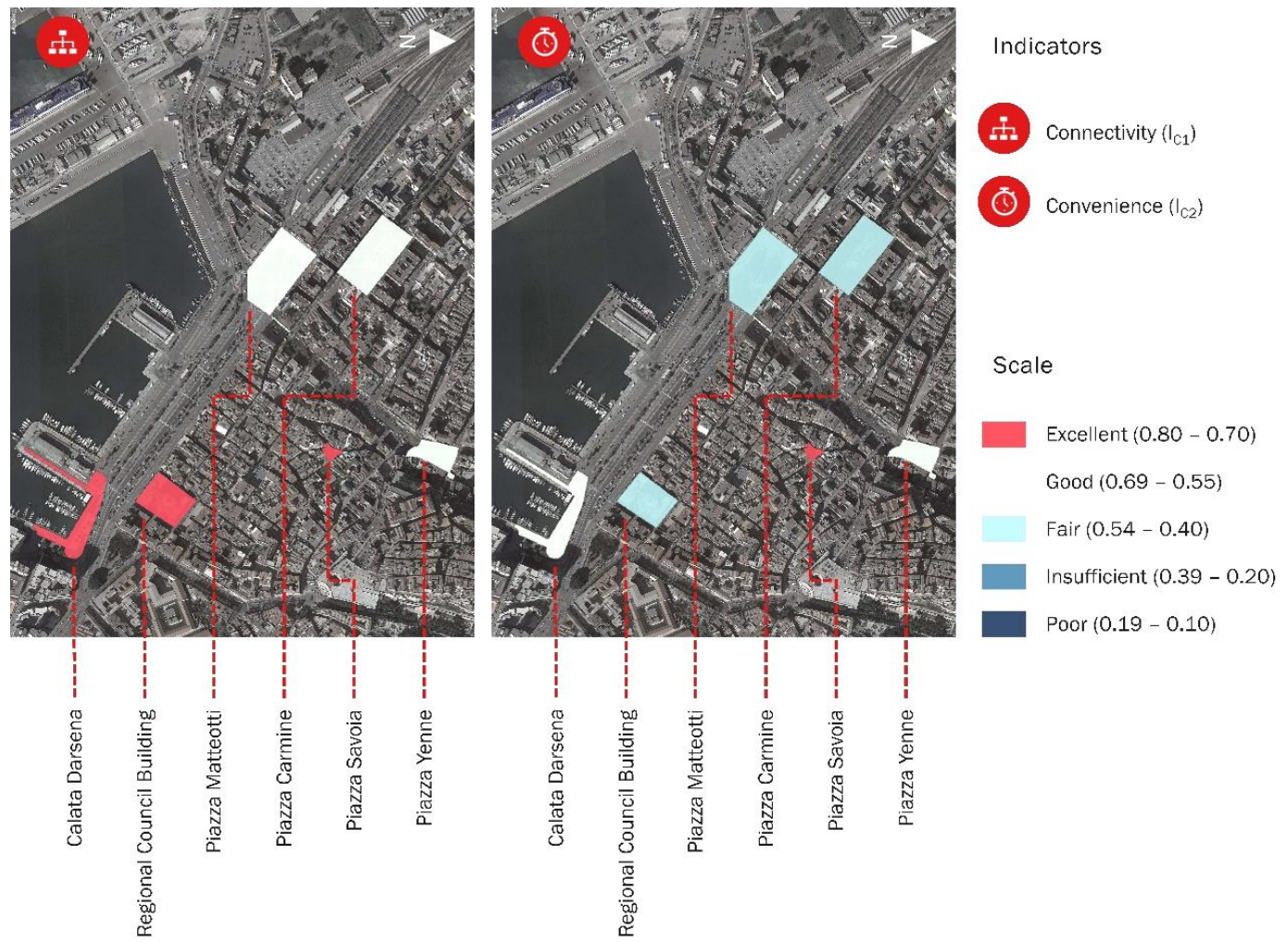

Figure 3. Representation of performance levels related to the indicators "connectivity" and "convenience".

A detailed review of comfort category properties (Figure 4) revealed critical aspects related to the presence of anti-social practices in Piazza del Carmine and Piazza Matteotti, to the absence of public lavatories in all the selected spaces, and the absence of drinking fountains in five of the selected spaces.

There were two drinking fountains located only in Piazza del Carmine within a distance of $70 \mathrm{~m}$ from the least advantageous points. Another critical element was the modest density of trees, measured by the tree coverage indicator. In particular, measurements related to the tree coverage indicator signified a relevant value in the ratio of urban space coverage (equal to $41 \%$ ) only in Piazza del Carmine.

The modest vegetation density was related to the contained variety of microclimatic conditions, and to a reduced impact on the acoustic and olfactory environment. In particular, these aspects were affected by the contiguity between the pedestrian space and congested passable lanes in Piazza Matteotti, Calata Darsena, and Piazza Yenne.

Finally, conditions of comfort in Calata Darsena were increased by the presence of a monumental fountain, which emerged as a distinctive spatial element that influenced the microclimate and reinforces imageability.

Varied conditions were described by the conviviality indicator (Figure 4). A relevant single aspect was the availability of play spaces (Table 6). The analysis underlined that Piazza del Carmine and the Regional Council Building enclosed surfaces particularly apt to accommodate children's informal and structured social activities.

Collective ludic activities were facilitated by the morphological regularity of available spaces, the consistency of the extent of these spaces with optimal social distances, and the absence of restrictions on the spontaneous use of space [19].

The presence of activities with extended service hours, along the edges of Piazza Yenne, Piazza Savoia, Calata Darsena, and the Regional Council Building space, was considered conducive to an increased level of vitality and safety through spontaneous vigilance and control of the selected spaces $[19,49]$. 

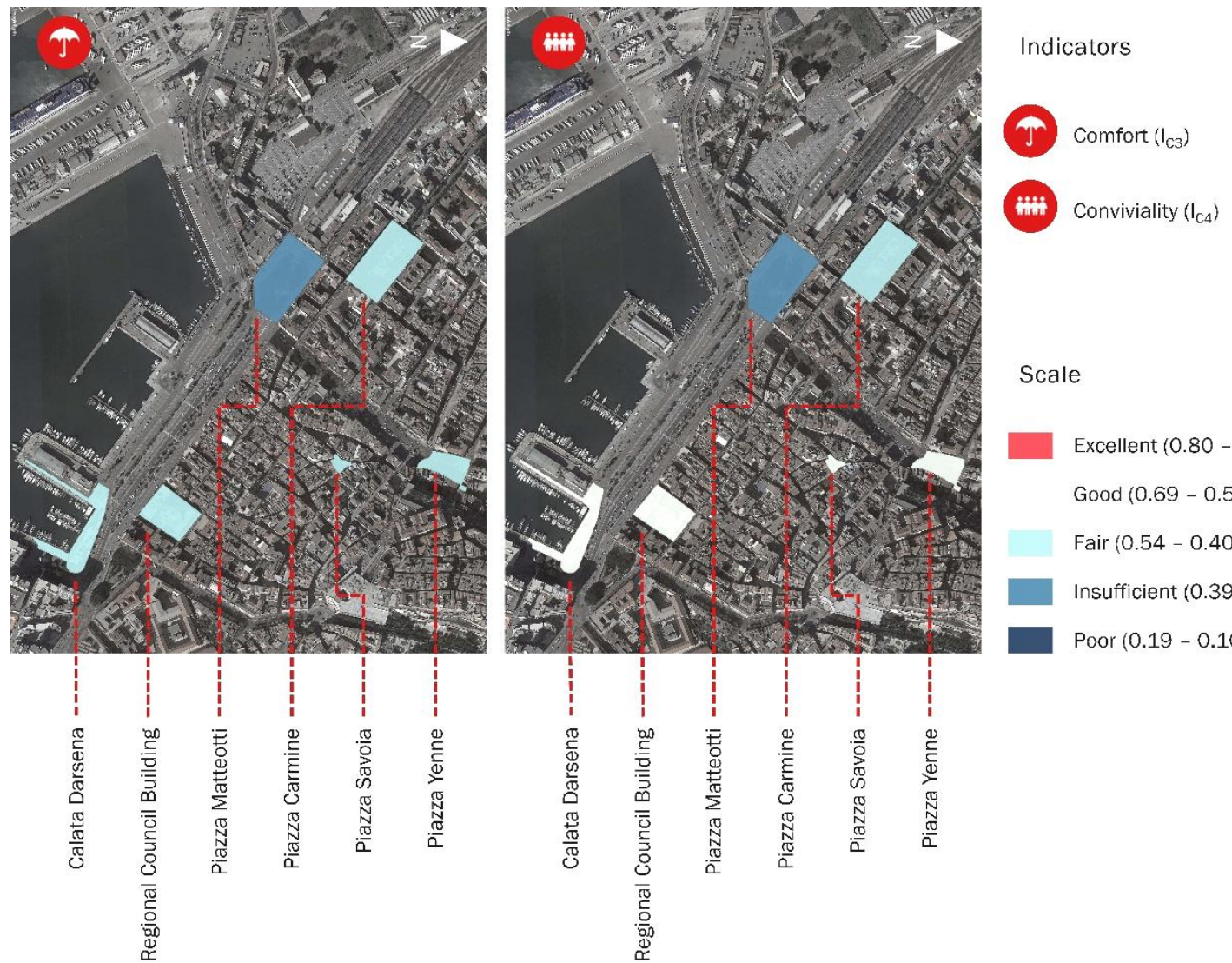

Conviviality $\left(\mathrm{I}_{\mathrm{C} 4}\right)$

Scale

Excellent $(0.80-0.70)$

Good (0.69 - 0.55)

Fair (0.54 - 0.40)

Insufficient $(0.39-0.20)$

Poor $(0.19-0.10)$

Figure 4. Representation of levels of performance related to the indicators comfort and conviviality.

Table 6. Results for the indicator "availability of clusters of space for play".

\begin{tabular}{|c|c|c|c|c|c|c|c|}
\hline \multicolumn{3}{|c|}{ Category } & \multicolumn{5}{|c|}{ Indicator } \\
\hline \multicolumn{3}{|c|}{ Conviviality } & \multicolumn{5}{|c|}{ Availability of Clusters of Space for Play } \\
\hline \multicolumn{3}{|c|}{ Measurement } & \multicolumn{2}{|c|}{ Range of Values } & \multicolumn{2}{|l|}{ Score } & $\begin{array}{c}\text { Level of } \\
\text { Performance }\end{array}$ \\
\hline \multicolumn{3}{|c|}{$\begin{array}{c}\mathrm{M}_{\mathrm{i}}=\left(\sum \mathrm{S}_{\mathrm{i}}\right) / \mathrm{n} \\
\mathrm{S}_{\mathrm{i}}=\text { Score of the ith sub-indicator } \\
\mathrm{n}=\text { Number of sub-indicators }\end{array}$} & \multicolumn{2}{|c|}{$\begin{array}{l}0.80 \geq \mathrm{M}_{\mathrm{i}} \geq 0.70 \\
0.69 \geq \mathrm{M}_{\mathrm{i}} \geq 0.55 \\
0.54 \geq \mathrm{M}_{\mathrm{i}} \geq 0.40 \\
0.39 \geq \mathrm{M}_{\mathrm{i}} \geq 0.20 \\
0.19 \geq \mathrm{M}_{\mathrm{i}} \geq 0.10\end{array}$} & $\begin{array}{l}0.8 \\
0.6 \\
0.5 \\
0.3 \\
0.1\end{array}$ & & $\begin{array}{c}\text { Excellent } \\
\text { Good } \\
\text { Fair } \\
\text { Insufficient } \\
\text { Poor }\end{array}$ \\
\hline \multirow{2}{*}{\multicolumn{2}{|c|}{ Sub-Indicators }} & \multicolumn{6}{|c|}{ Selected Urban Spaces } \\
\hline & & $\begin{array}{c}\text { Piazza del } \\
\text { Carmine }\end{array}$ & $\begin{array}{l}\text { Piazza } \\
\text { Yenne }\end{array}$ & $\begin{array}{c}\text { Regional } \\
\text { Council }\end{array}$ & $\begin{array}{c}\text { Calata } \\
\text { Darsena }\end{array}$ & $\begin{array}{l}\text { Piazza } \\
\text { Savoia }\end{array}$ & $\begin{array}{c}\text { Piazza } \\
\text { Matteotti }\end{array}$ \\
\hline $\mathrm{S}_{1}$ & Presence & 0.8 & 0.8 & 0.8 & 0.8 & 0.8 & 0.8 \\
\hline $\mathrm{S}_{2}$ & $\begin{array}{l}\text { Restriction on } \\
\text { use of space }\end{array}$ & 0.8 & 0.1 & 0.8 & 0.8 & 0.1 & 0.1 \\
\hline $\mathrm{S}_{3}$ & $\begin{array}{l}\text { Extent of free } \\
\text { surfaces }\end{array}$ & 0.7 & 0.1 & 0.7 & 0.7 & 0.3 & 0.3 \\
\hline $\mathrm{S}_{4}$ & $\begin{array}{l}\text { Morphological } \\
\text { Regularity }\end{array}$ & 0.8 & 0.5 & 0.8 & 0.5 & 0.1 & 0.3 \\
\hline Indi & $\begin{array}{l}\text { tor Aggregated } \\
\text { Score }\end{array}$ & 0.8 & 0.3 & 0.8 & 0.8 & 0.3 & 0.3 \\
\hline
\end{tabular}


However, a different situation was observed in Piazza del Carmine and Piazza Matteotti. Additionally, the absence of children's playground equipment was observed in all selected spaces, while a great variability was revealed regarding the presence of furniture, partitions, or spatial elements (i.e., steps, walls, ramps) available for informal activities (Table 7).

Table 7. Results for the indicator "availability of furniture for play".

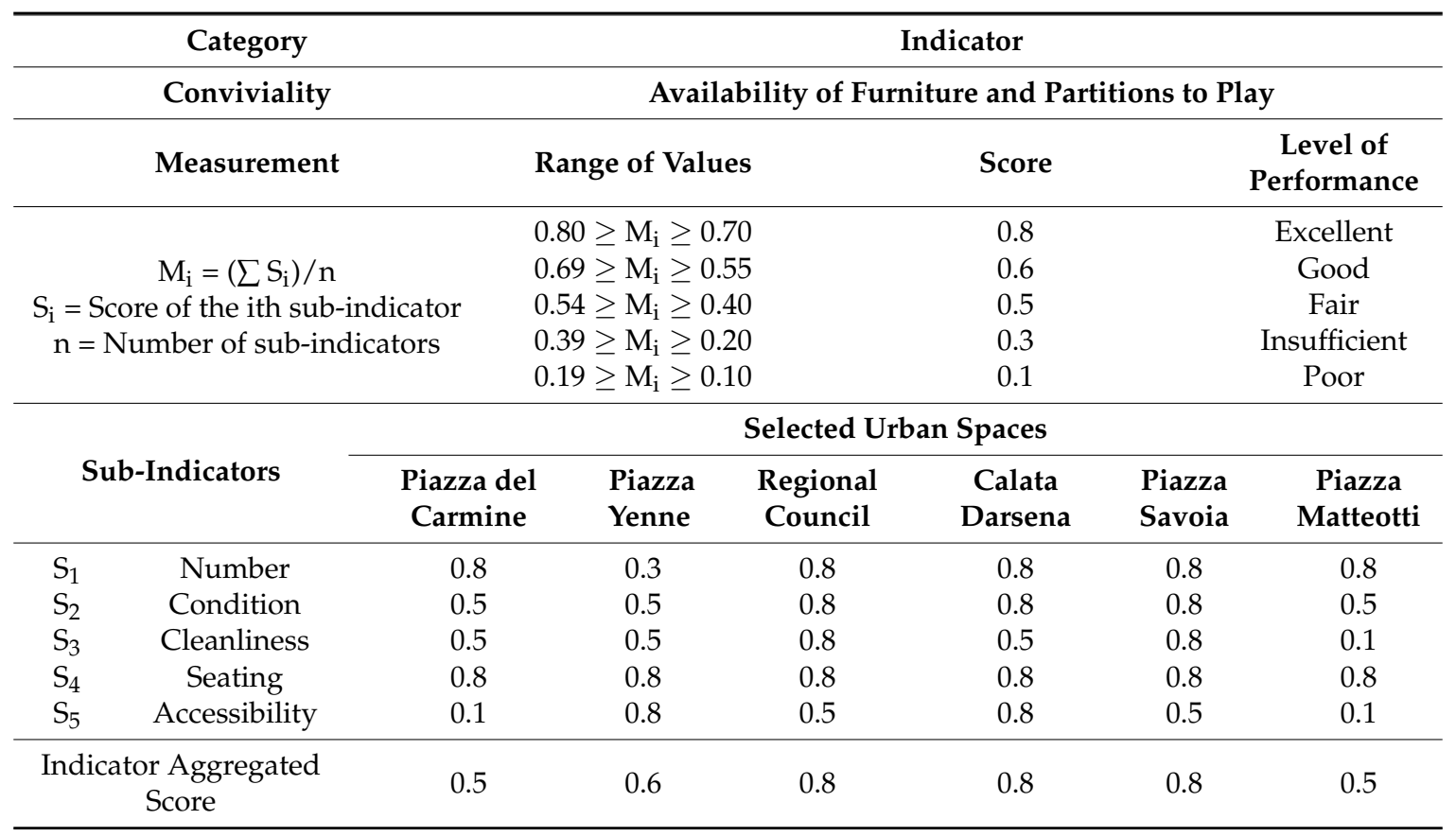

Trees, particularly relevant to the arrangement of space in Piazza Matteotti and Piazza del Carmine, represented a significant potential affordance that structured patterns of actions. Other significant affordances, both potential and utilized, were: the fountain, constituting a focal point within the space of Calata Darsena; the ramp connecting the two staggered levels of Piazza Savoia; the base of the obelisk in Piazza Yenne; and the bases of the sculptures beneath the Regional Council Building.

A relevant issue was represented by the levels of spatial and functional continuity among pedestrian surfaces and spaces and buildings enclosing the outer areas. In particular, the analysis of Calata Darsena, Piazza Matteotti, and Piazza del Carmine revealed the complete functional and spatial segregation of the pedestrian surfaces. An optimal level of spatial and functional continuity among buildings and the public space was finally observed in Piazza Savoia.

In general, we observed a positive situation regarding the availability of resting features and benches in the selected spaces. With regard to the sub-indicators of density, distribution of seats, condition, comfort, landscaping, cleanliness, coverage, position, and view, we observed relevant issues related to the distribution of seats with respect to edges, their mutual position, and comfort. In particular, benches were observed to be distant from defined spatial boundaries, hence not benefiting from the edge effect, and with the exception of Piazza Yenne, their mutual position did not structure a talkscape [19]. Therefore, it does not determine a seat configuration that facilitated contact among individuals while also regulating interactions.

An exception was represented by the absence of benches within the Regional Council Building space. This criticality was nevertheless partially compensated by the abundance of informal seats (e.g., partitions and bases of sculptures), identified as utilized affordances and as focal points in the patterns of activities within the space.

Results describe the significant criticalities regarding aspects of the built environment related to the conspicuousness category (Figure 5). 

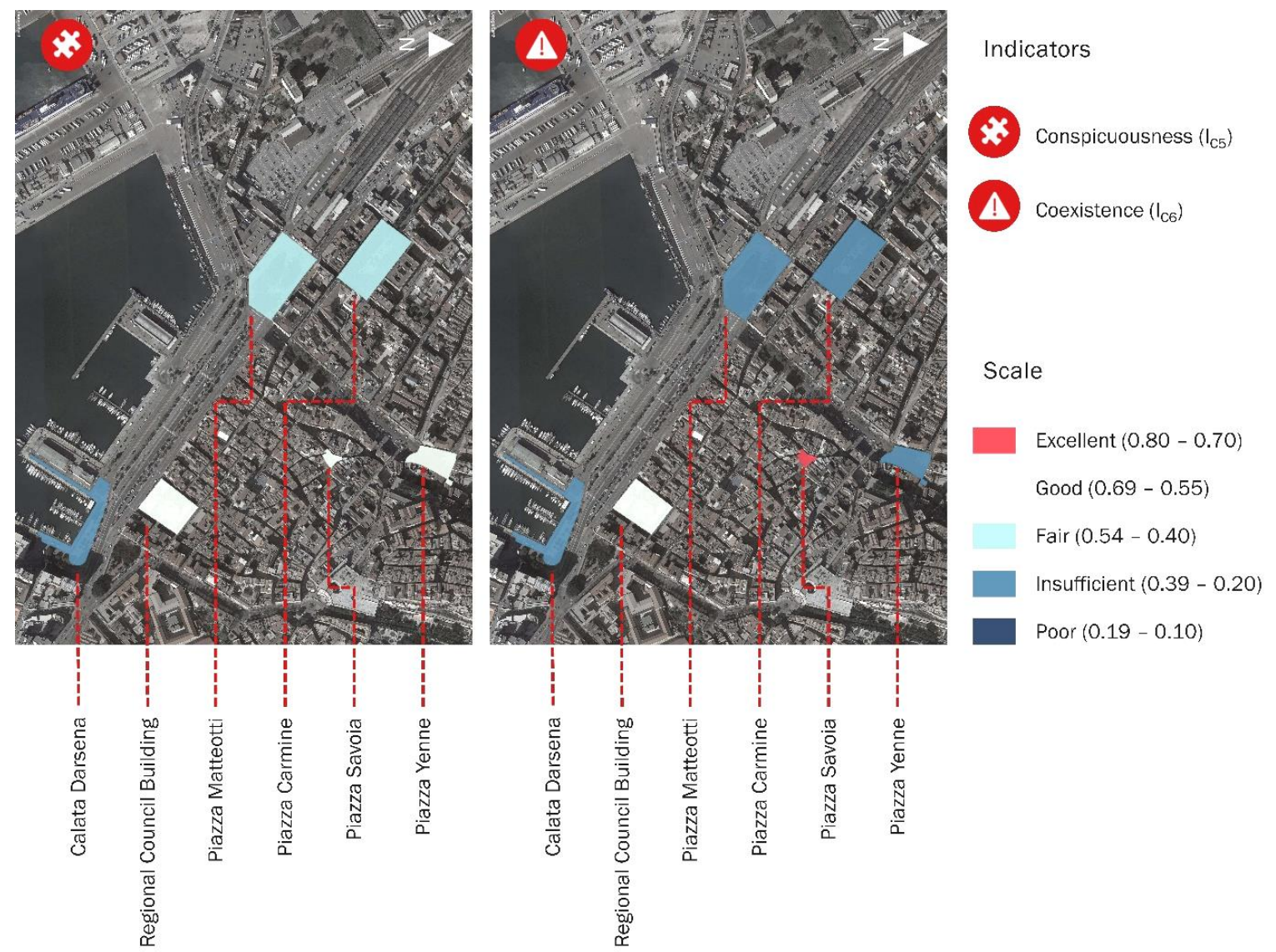

Figure 5. Representation of performance levels related to the indicators "conspicuousness" and "coexistence".

In particular, in Piazza del Carmine and Piazza Matteotti, the absence of significant outdoor activities reduced the vitality of the pedestrian space, influencing its imageability.

This aspect seemed to be correlated with the segregation of the pedestrian surface within the open space, and with the modest density of commercial activities and services along the boundaries of the public space. Nevertheless, a significant positive feature observed in all selected spaces was the presence of reference points and unique elements that reinforced the imageability of these places.

Another relevant element was the modest level of articulation of the edges of the pedestrian surfaces enclosed in the selected spaces, which also determined a reduced variety of spatial conditions.

Edges were determined via regularly aligned buildings (e.g., Piazza Yenne and Piazza Savoia), or regular lines of trees (e.g., Piazza del Carmine) (Table 8). A singular case was represented by the regional Council Building, whose complex shape reinforced the imageability of the space and the articulation of the edges, which were characterized by niches and repaired, enclosed spaces, and consequently, a variety of spatial conditions. 
Table 8. Results for the indicator "articulation of edges".

\begin{tabular}{|c|c|c|c|c|c|c|}
\hline Category & \multicolumn{6}{|c|}{ Indicator } \\
\hline Conspicuousness & \multicolumn{6}{|c|}{ Articulation of Edges } \\
\hline Equation & \multicolumn{3}{|c|}{ Range of Values } & Score & & $\begin{array}{c}\text { Level of } \\
\text { Performance }\end{array}$ \\
\hline $\mathrm{S}_{\mathrm{E}}=\left(\sum \mathrm{S}_{\mathrm{i}} \times \mathrm{L}_{\mathrm{i}}\right) / \mathrm{P}$ & \multicolumn{3}{|c|}{$0.80 \geq S_{E} \geq 0.70$} & 0.8 & & Excellent \\
\hline $\mathrm{P}=$ Perimeter & \multicolumn{3}{|c|}{$0.69 \geq \mathrm{S}_{\mathrm{E}} \geq 0.55$} & 0.6 & & Good \\
\hline $\mathrm{S}_{\mathrm{E}}=$ Interpolated Score & \multicolumn{3}{|c|}{$0.54 \geq \mathrm{S}_{\mathrm{E}} \geq 0.40$} & 0.5 & & Fair \\
\hline$S_{i}=$ Score for the ith condition & \multicolumn{3}{|c|}{$0.39 \geq S_{E} \geq 0.20$} & 0.3 & & Insufficient \\
\hline $\mathrm{L}_{\mathrm{i}}=$ Frequency of the ith condition (Table 2 ) & \multicolumn{3}{|c|}{$0.19 \geq S_{E} \geq 0.10$} & 0.1 & & Poor \\
\hline \multirow[b]{2}{*}{ Indicator } & \multicolumn{6}{|c|}{ Selected Urban Spaces } \\
\hline & $\begin{array}{l}\text { Piazza del } \\
\text { Carmine }\end{array}$ & $\begin{array}{l}\text { Piazza } \\
\text { Yenne }\end{array}$ & $\begin{array}{c}\text { Regional } \\
\text { Council }\end{array}$ & $\begin{array}{l}\text { Calata } \\
\text { Darsena }\end{array}$ & $\begin{array}{l}\text { Piazza } \\
\text { Savoia }\end{array}$ & $\begin{array}{c}\text { Piazza } \\
\text { Matteotti }\end{array}$ \\
\hline Articulation of edges & 0.6 & 0.5 & 0.8 & 0.3 & 0.6 & 0.3 \\
\hline
\end{tabular}

These different spaces also constitute a set of affordances, or opportunities, that enable different forms of social activities and interactions among children.

In general, the consistency of the composition and configuration of the selected spaces with the structural and functional dimensions of the human body was assessed as good. In Calata Darsena, the segregation of the pedestrian surface and the absence of façades articulated at eye level determined a weak relationship with the human scale.

Moreover, in Calata Darsena, Piazza Matteotti, and Piazza del Carmine, the spatial complexity was affected by the modest variety of spatial conditions and functions along edges. It was also affected by the modest interactivity of spatial boundaries, and thus, by the limited extent to which the compositional and functional characteristics of façades stimulated the different senses.

Relevant critical aspects also emerged regarding the synthetic indicator coexistence (Figure 5) $\mathrm{I}_{\mathrm{C} 6}$, resulting in conditions of discontinuity and uncomfortableness of the pedestrian environment that hindered children's independence and autonomy.

Features related to this condition were: (i) the absence of traffic calming measures; (ii) forms of separation among modes of movement not congruent with speed differentials [53], in particular in Calata Darsena and Piazza Matteotti, where a clear separation of pedestrian spaces from vehicular lanes were lacking; (iii) the reduced visibility of pedestrians at crossroads, related to an inadequate design of intersection points, not reinforced by specific patterns or architectural devices (e.g., widening of pavements, raised crosswalks, and distancing from parked cars), in particular in Piazza del Carmine and Piazza Yenne; (iv) the existence of numerous lines not corresponding to structured crossroads, in particular in Piazza del Carmine, Piazza Yenne, and Piazza Matteotti; and (v) the barrier effect, which caused the rupture of pedestrian space continuity determined by mobility spaces, and measured as a function of the number of traffic lanes and speed regulation.

The effect of discontinuity is relevant in Piazza Matteotti, Calata Darsena, Piazza Yenne, and on a limited scale in Piazza del Carmine.

In particular, in Piazza Matteotti and Piazza Darsena, it determines the segregation of the pedestrian space, hence the lack of spatial and functional continuity between the pedestrian space and the curtain of buildings that enclose it, and measured by the level of integration indicator, referred to the category conviviality (Figure 5).

A non-uniform situation is finally observed regarding the synthetic indicator related to the commitment category (Figure 6). In particular, issues were related to the maintenance levels of pedestrian surfaces and facilities, assessed as insufficient in Piazza Matteotti, in particular because of the poor conditions of regularity, slippery characteristics, stability, regularity, and roughness of pavement surfaces. In Piazza Matteotti, and the pedestrian surface enclosed by the Regional Council 
Building, a significant critical aspect was determined by scarcely illuminated portions of the pedestrian space, whose extension was estimated to range from $33 \%$ to $25 \%$ of the entire pedestrian surface.

A positive situation was observed regarding the condition and cleanliness of planted areas, even though the vegetation observed in the selected urban spaces lacked diversity.

The application of the proposed assessment framework revealed a general need for interventions, such as revitalization aimed at reinforcing the practicability of public spaces. In particular, the material, spatial, and contextual conditions to be addressed are: improvements to the diversity and extension of vegetation, the absence of public lavatories and drinking fountains, the distribution and positioning of seating in relation to spatial boundaries, the articulation of edges, the variety of spatial and microclimatic conditions, the relations of distinction and separation between mobility spaces and pedestrian facilities, the spatial and functional continuity between pedestrian spaces and private spaces, and the configuration of clusters of space available for ludic activities.
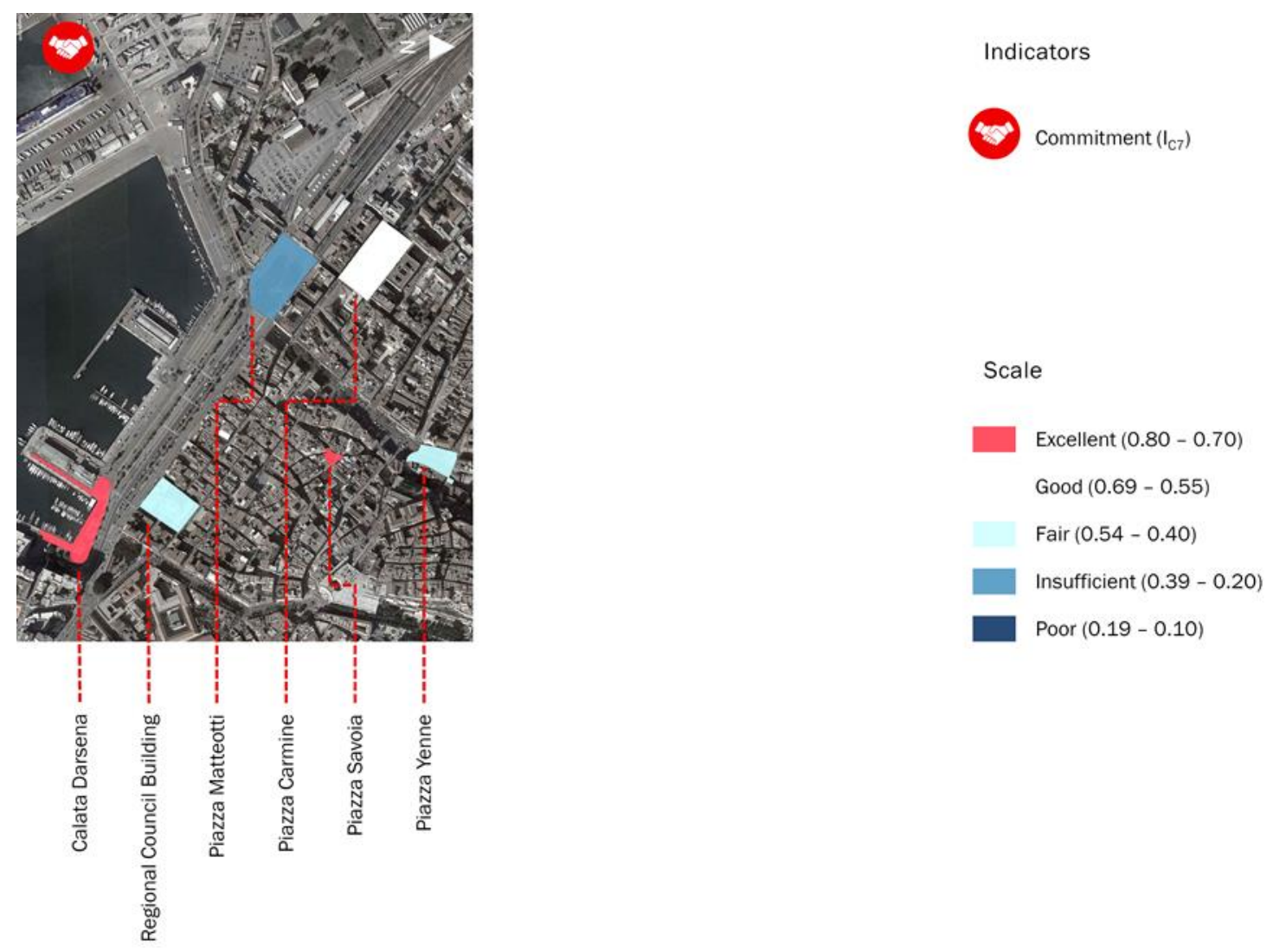

Figure 6. Representation of performance levels related to the indicator "commitment".

\section{Discussion}

The presented results refer to a defined set of public spaces, considered as discrete entities. Future stages of the research should focus on the adaptation for the SCOPE procedure to analysis of different purpose and scale and on its application for assessing the practicability of continuous networks of public spaces for measuring the variation of levels of practicability across a distinct portion of the urban structure.

Nevertheless, the application of this procedure to a significant set of specific spaces was useful to infer, by a comparison of results, general considerations related to the practicability of the built environment. In particular, the application to the selected spaces and the comparison among results enabled the individuation of frequent, diffused criticalities that generally influenced the potential of the central districts of Cagliari to encourage children's leisure activities and independent mobility. These criticalities included the absence of basic services and facilities, the competition for spaces 
among different modes of use and users, the absence or ambiguity of spatial patterns apt to support and organize different forms of contacts among individuals and of interactions among individuals and spaces, and the absence of spatial elements apt to articulate relations of contiguity and separation among pedestrian facilities and mobility spaces.

These categories of criticalities particularly affected the categories of comfort, conviviality, conspicuousness, and coexistence, and involved fundamental issues, central in determining the propensity of children to use spaces, namely comfort, environmental safety, vitality.

In particular, results indicated as relevant, general criticalities were the diversity and extension of green areas, the presence and condition of public lavatories and fountains, the distribution and positioning of seating in relation to spatial boundaries, the articulation of edges, the variety of spatial and microclimatic conditions, the relations of distinction and separation between mobility spaces and pedestrian facilities, the spatial and functional continuity between pedestrian spaces and private spaces, and the configuration of clusters of space available for ludic activities.

The application of the SCOPE procedure, thus, underlines needs and provides generic information regarding their relevance, determined by the deviation of synthetic and specific indicators from the optimal condition. A development of the procedure was required to account for the relative importance of indicators and to provide a precise indication of the priority of needs to be addressed, measured as a function of the deviation from the optimum condition and of the indicator relative importance.

The individuation of needs is instrumental to the definition of objectives for actions of regeneration of the public spaces, and to the determination of the priority of interventions. The application of the SCOPE procedure can orient these actions according to three distinct perspectives: (i) individuation of specific critical spaces and individuation of major criticalities within these spaces for defining objectives of punctual interventions of regeneration; (ii) individuation, by comparing a set of spaces, of frequent criticalities and definition of objectives for diffused actions of amelioration focused on specific microscale features across a pre-determined portion of the urban structure; and (iii) individuation of criticalities related to medium-scale contextual factors and definition of objectives for global, integrated interventions of urban renewal.

These perspectives reflected the structuring of the procedure as a framework of indicators that measured microscale features specific to single spaces and of indicators focused on conditions determined by medium-scale contextual factors.

This aspect incorporated the idea that a space's practicability depended both on its inherent qualities, determined by its specific compositional, functional, and spatial features, and on its endowed qualities, determined by accessibility, connectivity, and by configuration, density, and land-use patterns of the surrounding environment.

Moreover, the theoretical premises of the SCOPE procedure incorporate the motivation for interventions aimed at reinforcing practicability of the public spaces so as to integrate children's independent activities within spaces intensely used by other groups of users: the idea that independent mobility and structured, informal, group ludic activities within urban spaces, affording the experimentation, exploration of spaces and interactions, are a condition for the development of children's cognitive, imaginative, and creative potential, and for the construction of their social and individual identities. In conclusion, the SCOPE procedure incorporates a methodological framework that can be adapted and applied in different contexts in order to support an evaluation of the potential of the built environment to accommodate children's activities and to support punctual or diffused interventions of regeneration and renovation. The replicability of this assessment framework depends on the procedural character of the proposed method. The SCOPE procedure, in fact, is conceived as a framework that incorporates both a general matrix that organizes a set of indicators and sub-indicators and a sequence of preliminary actions aimed at adapting the matrix to the context of the analysis, restructuring the tool according to the characterization of the case study and to the definition of aspects of the public space individuated as the object of the assessment through the stakeholder sessions. These characters of replicability and adaptability of the SCOPE procedure will be reinforced by organizing 
the stakeholder sessions as focus groups aimed at individuating a set of significant spatial, functional, material, and configurational properties, and at establishing their relative importance, thus weighting scores assigned to the related indicators.

\section{Conclusions}

This contribution presents the results of the preliminary stages of a study aimed at structuring an assessment framework, the Survey on Conditions for Practicable Environments (SCOPE), and at defining a synthetic index of practicability, the ISCOPE index. The ISCOPE index and the SCOPE procedure incorporate a methodological framework to understand the conditions for children-oriented urban spaces and to support and orient policies to optimize performance of the built environment. The SCOPE procedure and the ISCOPE index introduce into the smart-city paradigm the concept of practicability and develop indicators, such as availability of clusters of space for play, availability of furniture and partitions to play, availability of informal seats, and articulation of edges, intended to measure material, functional, and spatial conditions of public spaces that incorporate affordances for children's social, leisure activities and are thus conducive to increasing children's autonomy and capabilities.

The concept of practicability is central to the smart-city paradigm since it addresses the fundamental issues of children's right to the city and of the built environment's performance equality and inclusivity [24]. In fact, the concept of practicability incorporates both the demand for a children-sensitive perspective in the project of public spaces and the conceptualization of the inclusivity of public spaces as their potential to accommodate and enable children's independent mobility and informal and structured, individual, and collective ludic activities. This conceptualization emphasizes the importance of exploration and appropriation of public spaces through play as a condition for the development of children's cognitive, imaginative, and creative potential, and for the construction of their social and individual identities. This preliminary stage of the research is aimed at configuring a standardized procedure, defining a layout, selecting indicators, and defining evaluation scales and parameters.

The application to the case study revealed that the structure of the procedure, the layout of the assessment framework, and the selection of indicators were instrumental in configuring a valid tool for identifying critical aspects of the public space, and for supporting the implementation of interventions to optimize the built environment's performance and practicability. In fact, the utilization of the SCOPE procedure clarifies the content of interventions required to produce and increase spatial, functional, and material conditions that incorporate affordances for children's ludic activities within public spaces.

Nevertheless, the configuration of the proposed methodology and its application to the case study reveals numerous critical factors. These can be summarized as: (i) variety and correlation of aspects influencing the tendency of children to engage in activities in public spaces, (ii) selection and weighting of indicators, (iii) definition of criteria for assessing qualitative indicators, (iv) normalization of measures and assessments determined for the selected indicators, and (v) validation of results.

Therefore, the findings of this preliminary study constitute the basis for further investigations. In particular, future research will focus on five issues: (i) determining the relative importance of the selected indicators to capture the different effects of specific properties of the built environment on children's tendency to engage in activities within the public space; (ii) relating the importance of properties of the built environment with children's individual characteristics, such as age, purpose, or spatial familiarity; (iii) recalibrating the data collection and evaluation phases of the indicators to extend the methodology application to vast portions of the urban structure; (iv) defining value functions and/or quality thresholds for converting values and assessments of the qualitative and quantitative indicators in homogeneous scores to aggregate indicators in a synthetic index of practicability; and (v) establishing a validation procedure to measure whether, and to what extent, the scores assigned to a space correspond to the level of practicability perceived by children. Further development of the proposed methodology is intended to improve the objectivity, measurability, and reproducibility 
of the $\mathrm{I}_{\mathrm{SCOPE}}$ index and its representativeness of conditions conducive to children's autonomy and independent social activities. The objective is to reinforce the relevance of the concept of practicability to the implementation of the smart-city paradigm, both as a category for understanding child-friendly urban spaces, and as a condition for consolidating inclusion and equality within sustainable communities.

Author Contributions: This paper is the result of the joint work of the authors. Conceptualization, C.G. and A.A.; Data curation, C.G., A.A. and M.C.; Formal analysis, C.G.; Investigation, M.C.; Methodology, C.G., A.A. and M.C.; Supervision, C.G. and M.C.; Validation, A.A.; Writing-original draft, C.G., A.A. and M.C.; Writing-review \& editing, C.G.

Funding: This study was funded by the MIUR (Ministry of Education, Universities and Research [Italy]) through two projects: (1) Governing tHe smart city: a gOvernance-centred approach to SmarT urbanism-GHOST (Project code: RBSI14FDPF; CUP Code: F22I15000070008), financed with the SIR (Scientific Independence of Young Researchers) programme. (2) "CAGLIARI2020" (Project code: PON04a2_00381). We authorize the MIUR to reproduce and distribute reprints for governmental purposes, notwithstanding any copyright notations thereon. Any opinions, findings, and conclusions or recommendations expressed in this material are those of the authors, and do not necessarily reflect the views of the MIUR. This study was also supported by the project "Healthy Cities and Smart Territories," founded by the Foundation of Sardinia and Autonomous Region of Sardinia (Fondazione di Sardegna-Convenzione triennale tra la Fondazione di Sardegna e gli Atenei Sardi Regione Sardegna 2016).

Conflicts of Interest: The authors declare no conflict of interest. The founding sponsors had no role in the design of the study, the collection, analyses, or interpretation of the data, in writing the manuscript, or in the decision to publish the results.

\section{References and Notes}

1. Lefebvre, H. The right to the city. In Writings on Cities; Lefebvre, H., Kofman, E., Lebas, E., Eds.; Blackwell: Cambridge, MA, USA, 1995; pp. 63-184, ISBN 978-0631191889.

2. Pavia, R. Il Passo della Città, 1st ed.; Donzelli Editore: Roma, Italy, 2015; pp. 15-30, ISBN 9788868431693.

3. Secchi, B. La Città dei Ricchi e la Città dei Poveri, 3rd ed.; Editori Laterza: Bari, Italy, 2014; pp. 21-30, ISBN 978-8858106648.

4. Kirk, M. How to Design Cities for Children. Available online: https://www.citylab.com/design/2018/02/ how-to-design-cities-for-children/552086/ (accessed on 2 April 2018).

5. Hillier, B. Space Is the Machine: A Configurational Theory of Architecture, 1st ed.; Space Syntax: London, UK, 2007; pp. 138-170, ISBN 978-0-9556224-0-3.

6. Tonucci, F. Citizen child: Play as Welfare Parameter for Urban Life. Topoi 2005, 24, 183-195. [CrossRef]

7. ARUP. Cities Alive: Designing for Urban Childhoods; ARUP: London, UK, 2017. Available online: https://www. arup.com/perspectives/publications/research/section/cities-alive-designing-for-urban-childhoods (accessed on 4 April 2018).

8. Noora, P. Thinking with broken glass: Making pedagogical spaces of enchantment in the city. Environ. Educ. Res. 2017, 23, 1391-1401. [CrossRef]

9. Frabboni, F.; Pinto Minerva, F. La Scuola Dell'infanzia, 1st ed.; GLF editori Laterza: Bari, Italy, 2008; ISBN 8842086487.

10. Shaw, B.; Bicket, M.; Elliott, B.; Fagan-Watson, B.; Mocca, E.; Hillman, M. Children's Independent Mobility: An International Comparison and Recommendations for Action; Policy Studies Institute, University of Westminster: London, UK, 2015. Available online: http://www.psi.org.uk/docs/7350_PSI_Report_CIM_final.pdf (accessed on 12 September 2018).

11. Alexander, C.; Ishikawa, S.; Silverstein, M.; Jacobson, M.; Fiksdahl-King, I.; Ange, S. A Pattern Language: Towns—Building—Construction; Oxford Press: New York, NY, USA, 1977; pp. 58-109, ISBN 13:978019501919-3.

12. Tantawy, M.A.; Hussein, N.A.; Mahrous, M.A. Influence of Urban Fabric on Child's Upbringing: A Comparative Analysis between Modern and Traditional City. Int. J. Hum. Soc. Sci. 2016, 10, 2079-2082.

13. Janssen, I.; Ferrao, T.; King, N. Individual, family, and neighborhood correlates of independent mobility among 7 to 11-year-olds. Prev. Med. Rep. 2016, 3, 98-102. [CrossRef] [PubMed]

14. Lin, E.-Y.; Witten, K.; Oliver, M.; Carroll, P.; Asiasiga, L.; Badland, H.; Parker, K. Social and built-environment factors related to children's independent mobility: The importance of neighbourhood cohesion and connectedness. Health Place 2017, 46, 107-113. [CrossRef] [PubMed] 
15. Sharmin, S.; Kamruzzaman, M. Association between the built environment and children's independent mobility: A meta-analytic review. J. Transp. Geogr. 2017, 61, 104-117. [CrossRef]

16. Christian, H.; Zubrick, S.R.; Foster, S.; Giles-Corti, B.; Bull, F.; Wood, L.; Knuiman, M.; Brinkman, S.; Houghton, S.; Boruff, B. The influence of the neighborhood physical environment on early child health and development: A review and call for research. Health Place 2015, 33, 25-36. [CrossRef] [PubMed]

17. Moura, F.; Cambra, P.; Gonçalves, A.B. Measuring walkability for distinct pedestrian groups with a participatory assessment method: A case study in Lisbon. Landsc. Urban Plan. 2017, 157, 282-296. [CrossRef]

18. Jun, H.J.; Hur, M. The relationship between walkability and neighborhood social environment: The importance of physical and perceived walkability. Appl. Geogr. 2015, 62, 115-124. [CrossRef]

19. Gehl, J. Cities for People; Island Press: Washington, DC, USA, 2013; ISBN 9781597265737.

20. Blečić, I.; Cecchini, A.; Congiu, T.; Fancello, G.; Trunfio, G.A. Evaluating walkability: A capability-wise planning and design support system. Int. J. Geogr. Inf. Sci. 2015, 29, 1350-1374. [CrossRef]

21. Blečić, I.; Cecchini, A.; Congiu, T.; Fancello, G.; Trunfio, G.A. Walkability explorer: Application to a case-study. In Computational Science and Its Applications. In Proceedings of the 15th International Conference on Computational Science and Its Applications-ICCSA 2015, Banff, AB, Canada, 2-25 June 2015; pp. 758-770.

22. Garau, C.; Pavan, V.M. Evaluating Urban Quality: Indicators and Assessment Tools for Smart Sustainable Cities. Sustainability 2018, 10, 575. [CrossRef]

23. Laaksoharju, T.; Rappe, R. Trees as affordances for connectedness to place-A framework to facilitate children's relationship with nature. Urban For. Urban Green. 2017, 28, 150-159. [CrossRef]

24. Annunziata, A.; Garau, C. Understanding Kid-Friendly Urban Space for a More Inclusive Smart City: The Case Study of Cagliari (Italy). In International Conference on Computational Science and Its Applications, Proceedings of the 18th International Conference on Computational Science and Its Applications-ICCSA 2018, Melbourne, VIC, Australia, 2-5 July 2018; Gervasi, O., Murgante, B., Misra, S., Stankova, E., Torre, C.M., Rocha, A.M.A.C., Taniar, D., Apduhan, B.O., Tarantino, E., Ryu, Y., Eds.; Springer: Cham, Switzerland, 2018; pp. 589-605.

25. UNICEF Innocenti Research Centre. Building Child Friendly Cities: A Framework for Action; UNICEF Innocenti Research Centre: Florence, Italy, 2004. Available online: https://www.unicef-irc.org/publications /416building-child-friendly-cities-a-framework-for-action.html (accessed on 12 May 2018).

26. United Nations. Convention on the Rights of the Child. General Assembly Resolution 44/25 of 20 November 1989. Available online: https://www.ohchr.org/Documents/ProfessionalInterest/crc.pdf (accessed on 26 April 2018).

27. Sen, A. Capability and well-being. In The Quality of Life; Nussbaum, M., Sen, A., Eds.; Clarendon Press: Oxford, UK, 1993; pp. 30-53.

28. Careri, F. Walkscapes: Camminare Come Pratica Estetica; G. Einaudi Editore: Torino, Italy, 2006; pp. 3-28, ISBN 978-8806180676.

29. Hall, C.M.; Ram, Y. Walk score ${ }^{\circledR}$ and its potential contribution to the study of active transport and walkability: A critical and systematic review. Transp. Res. Part D Transp. Environ. 2018, 61 Pt B, 310-324. [CrossRef]

30. Taleai, M.; Amiri, E.T. Spatial multi-criteria and multi-scale evaluation of walkability potential at street segment level: A case study of Tehran. Sustain. Cities Soc. 2017, 31, 37-50. [CrossRef]

31. Clifton, K.J.; Smith, A.D.L.; Rodriguez, D. The development and testing of an audit for the pedestrian environment. Landsc. Urban Plan. 2007, 80, 95-110. [CrossRef]

32. Pikora, T.; Giles-Corti, B.; Bull, F.; Knuiman, M.; Jamrozik, K.; Donovan, R. Survey of the Physical Envi-ronment in Local Neighbourhoods SPACES Instrument: Observers Manual; The University of Western Australia: Nedlands, Australia, 2000. Available online: https:/ / activelivingresearch.org/sites/default/files/SPACES_ Observation_Manual.pdf (accessed on 12 April 2018).

33. Cain, K.L.; Gavand, K.A.; Conway, T.L.; Geremia, C.M.; Millstein, R.A.; Frank, L.D.; Sallis, J.F. Developing and validating an abbreviated version of the Microscale Audit for Pedestrian Streetscapes (MAPS-Abbreviated). J. Transp. Health 2017, 5, 84-96. [CrossRef] [PubMed]

34. Saelens, B.E.; Frank, L.D.; Auffrey, C.; Whitaker, R.C.; Burdette, H.L.; Colabianchi, N. Measuring physical environments of parks and playgrounds: EAPRS instrument development and inter-rater reliability. J. Phys. Act. Health 2006, 3, 190S-207S. [CrossRef] [PubMed] 
35. Rosenberg, D.; Ding, D.; Sallis, J.F.; Kerr, J.; Norman, G.J.; Durant, N.; Harris, S.K.; Saelens, B.E. Neighborhood environment walkability scale for youth (NEWS-Y): Reliability and relationship with physical activity. Prev. Med. 2009, 49, 213-218. [CrossRef] [PubMed]

36. Labbucci, A. Camminare, una Rivoluzione; Donzelli Editore: Roma, Italy, 2011; pp. 7-26, ISBN 978-886036628-3.

37. Geurs, K.T.; Van Wee, B. Accessibility evaluation of land-use and transport strategies: Review and research directions. J. Transp. Geogr. 2004, 12, 127-140. [CrossRef]

38. Jabbari, M.; Fonseca, F.; Ramos, R. Combining multi-criteria and space syntax analysis to assess a pedestrian net-work: The case of Oporto. J. Urban Des. 2018, 23, 23-41. [CrossRef]

39. Talavera-Garcia, R.; Soria-Lara, J.A. Q-PLOS, developing an alternative walking index. A method based on urban design quality. Cities 2015, 45, 7-17. [CrossRef]

40. Ewing, R.; Handy, S. Measuring the unmeasurable: Urban design qualities related to walkability. J. Urban Des. 2009, 14, 65-84. [CrossRef]

41. Ewing, R.; Hajrasouliha, A.; Neckerman, K.M.; Purciel-Hill, M.; Greene, W. Streetscape features related to pedestrian activity. J. Plan. Educ. Res. 2016, 36, 5-15. [CrossRef]

42. Battista, G.A.; Manaugh, K. Stores and mores: Toward socializing walkability. J. Transp. Geogr. 2018, 67, 53-60. [CrossRef]

43. Cervero, R.; Kockelman, K. Travel demand and the 3Ds: Density, diversity and design. Transp. Res. Part D Transp. Environ. 1997, 2, 199-219. [CrossRef]

44. Ewing, R.; Connors, M.; Goates, J.; Hajrasouliha, A.; Neckerman, K.; Nelson, A.; Green, W. Validating urban design measures. In Proceedings of the Transportation Research Board 92nd Annual Meeting, Washington, DC, USA, 13-17 January 2013; pp. 13-1662.

45. Gardner, K.; Johnson, T.; Buchan, K.; Pharoah, T. Developing a pedestrian strategy for London. In Proceedings of the Seminar B, 24th European Transport Forum, Brunel University, Uxbridge, UK, 2-6 September 1996.

46. Kamel, M.A.E. Encouraging walkability in GCC cities: Smart urban solutions. Smart Sustain. Built Environ. 2013, 2, 288-310. [CrossRef]

47. The indicator Level of integration refers to 3 distinct conditions: (i) Integrated: Continuity among pedestrian spaces and buildings along edges; (ii) Filtered: Continuity of the view and limitations of movements among pedestrian spaces and buildings; Separated: (iii) Discontinuity or segregation.

48. The indicator Articulation of edges refers to 6 distinct conditions: (i) Articulated: Presence of numerous and diversified spatial interfaces; (ii) Varied: Non regular alignment of buildings or spatial elements and/or presence of some transition spaces; (iii) Reinforced: Regular edges reinforced by regularly spaced elements; (iv) Regular: Elements aligned defining regular edges; (v) Not defined: Punctual elements determining an unclear edge; (vi) Absent: Absence of devices reinforcing edges.

49. Jacobs, J. The Death and Life of Great American Cities; Random House: New York, NY, USA, 1961; ISBN 9780679644330.

50. Lynch, K. The Image of the City, 2nd ed.; MIT Press: Cambridge, MA, USA, 1964; ISBN 9780262620017.

51. UNICEF: Declaration of Rotterdam on the Role of Local and Regional Authorities in the Establishment of Child Friendly Communities. 2008. Available online: https:/ /www.unicef.it/Allegati/Declaration_of_ Rotterdam_2008_1.pdf (accessed on 2 January 2018).

52. Coni, M.; Garau, C.; Pinna, F. How has Cagliari Changed Its Citizens in Smart Citizens? Exploring the Influence of ITS Technology on Urban Social Interactions. In International Conference on Computational Science and Its Applications, Proceedings of the 18th International Conference on Computational Science and Its Applications-ICCSA 2018, Melbourne, VIC, Australia, July 2-5, 2018; Gervasi, O., Murgante, B., Misra, S., Stankova, E., Torre, C.M., Rocha, A.M.A.C., Taniar, D., Apduhan, B.O., Tarantino, E., Ryu, Y., Eds.; Springer: Cham, Switzerland, 2018; pp. 573-588.

53. Marshall, S. Streets and Patterns, 1st ed.; Spon Press: New York, NY, USA, 2005; pp. 191-220, ISBN 0-203-33785-9.

(C) 2018 by the authors. Licensee MDPI, Basel, Switzerland. This article is an open access article distributed under the terms and conditions of the Creative Commons Attribution (CC BY) license (http://creativecommons.org/licenses/by/4.0/). 